Available online on 15.11.2017 at http://jddtonline.info
Journal of Drug Delivery and Therapeutics
Open Access to Pharmaceutical and Medical Research
$\begin{gathered}\text { o 2011-17, publisher and licensee JDDT, This is an Open Access article which permits unrestricted } \\ \text { non-commercial use, provided the original work is properly cited }\end{gathered}$

\title{
NOVEL MULTIPARTICULATE DRUG DELIVERY SYSTEM OF CARVEDILOL AS ANTIHYPERTENSIVE DRUG
}

\author{
Abdul Nasir Kurnool ${ }^{1}$, Rakesh Kumar Jat ${ }^{1}$, C Narendra ${ }^{2}$ \\ ${ }^{1}$ Institute of Pharmacy, Shri Jagdishprasad Jhabarmal Tibrewala University Jhunjhunu, Rajasthan, 313001, India \\ ${ }^{2}$ Viswesvarapura institute of pharmaceutical sciences, Bangalore, India
}

\section{ABSTRACT}

The main objectives of present work was to design and evaluate pellets of Carvedilol in order to increase patient compliance and therapeutically benefits. The pellets were made by the sub-coating with sodium bicarbonate and hydroxyl propyl methyl cellulose which was utilized to keep the spheres in stomach for long time. Hence sodium bicarbonate and hydroxyl propyl methyl cellulose are the key ingredients of this dissertation work. In vitro release trials were evaluated in response to check release of drug from the drug coated spheres. The release pattern of batches T1 to T6 was observed to vary due to variation in the concentration of HPMC 5cps, low substituted HPC and PVP K30. The trials T1-T3 showed the slow drug release due to combination of PVP K30 with low substituted HPC and HPMC 5cps; while the formulation T4-T6 showed the good release behavior as compare to T1-T3.

Keywords: Carvedilol, Multiparculate, Pellets, TLC, HPLC.

Article Info: Received 13 Aug, 2017; Review Completed 29 Oct, 2017; Accepted 08 Nov, 2017; Available online 15 Nov, 2017

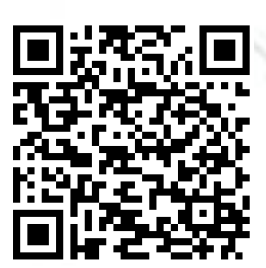

Cite this article as:

Kurnool AN, Jat RK, Narendra C Novel multiparticulate drug delivery system of carvedilol as antihypertensive drug, Journal of Drug Delivery and Therapeutics. 2017; 7(6):49-55

DOI: http://dx.doi.org/10.22270/jddt.v7i6.1511

*Address for Correspondence

Abdul Nasir Kurnool, Institute of Pharmacy, Shri JJT University Jhujhunu Raj-313001, Tel.: 9481547932, E-mail address: nasirmpharma@gmail.com

\section{INTRODUCTION}

Carvedilol is antihypertensive drug used for mild to moderate hypertension. It is beta blocker with additional alpha 1 blocking activity. It is administer orally and is immediately absorb from GIT. Peak medication impacts occur in 90 min of single units. In single unit study, in subjects administering with $5 \mathrm{mg}$ and $10 \mathrm{mg}$ drug, the mean peak concentrations $\left(\mathrm{C}_{\max }\right)$ were 59 (range: 29112) and 121 (range: 58-271) $\mathrm{ng} / \mathrm{mL}$, respectively, occurs at a mean time $\left(\mathrm{T}_{\max }\right)$ of $1.6 \mathrm{~h}$ for both strengths.<smiles>COc1ccccc1OCCNCC(O)COc1cccc2[nH]c3ccccc3c12</smiles>

1-(9H-Carbazol-4-yloxy)-3-[[2-(2-methoxyphenoxy) ethyl]-amino]- 2-propanol

Multiparticulate drug shipping device (MDDS), have been extensively used for administering via oral path, it includes wide variety of smaller discrete subunits which has exceptional homes. It's specifically primarily based on subunits like microspheres ${ }^{1,2}$, granules, pellets, beads 3, 4, 5 minitab and spheroids. Such kind of subunits gives numerous advantages as evaluate to monolithic kind gadgets. In MDDS, active pharmaceutical substances are get divides into range of subunits, usually which has number of round units which have diameter of about $0.052 \mathrm{~mm}$ to $1.98 \mathrm{~mm}$. to make use of or to administer total dose these subunits to be compacted in capsules or get crammed right into a optimistic packs or well encapsulated ${ }^{6}$.

The composition including multicomponent MDDS is feasible as it famous numerous mode of movement, it shows synergistic or additive effect, minimizes man or woman's doses and limit the facet results. Though its miles more luxurious as compare to single treatment options within the quick term, it minimizes treatment failure ratio, reduce charge of case fatality and drop in improvement of resistance for designing of recent devices in long time type therapy ${ }^{7,8}$. 
Various formulation parameters that play a crucial role in the successful formulation of drugs are aqueous solubility, stability at ambient temperature and humidity, photo stability, compatibility with solvent and excipients

Multiple unit dosage units are pharmaceutical compositions in that the lively substance is available as a spread of smaller independent multiple devices. To provide the recommended each day dose, these form of small units are get well stuffed into a normal sachet and compressed or encapsulated right into a strong dosage shape. A couple of units are discrete small debris which give the multiple unit kind system. Additionally they display range of benefits over single-unit kind systems due to of their very smaller length. A couple of gadgets are much less depending on gastric emptying, which ends up in minimal intra and inter -issue type variant in gastro-intestinal transit kind. They also uniformly disbursed and really minimum assume to reason nearby type irritation.

There are a couple of justifications for designing a active substance as a multiple unit gadget for e.g., to improve disintegration type inside the belly, or to show provide a comfortable, fast disintegrating kind tablet which get dissolve in aqueous medium early to swallowing which also can useful resource compliance with elder volunteers and small Childs. Multiple unit device gives well reproducible pharmacokinetic sample than monolithically or conventional formulations. After process of disintegration which observes inside a very much less minutes even in seconds, the character subunits get bypass immediately via a GI tract. If those debris or units have diameter not $>1.99 \mathrm{~mm}$, they have potential to left the stomach in non-stop way, even though the pylorus is being closed. These results in much less inter and intra subject versions in bioavailability and plasma stages. The main objectives of present work was to design and evaluate pellets of Carvedilol in order to increase patient compliance and therapeutically benefits.

\section{MATERIALS AND METHODS}

The following materials were used for the experimental work done.

Table 1: List of Chemicals used

\begin{tabular}{|c|c|c|c|}
\hline S.N. & Name of chemical & Grade & Manufacturer / Distributor \\
\hline 1 & Carvedilol & USP & Aurobindo Pharma, Hyderabad \\
\hline 2 & HPMC E5LV & USP/NF, EP,JP & Signet Chemical Corporation, Mumbai \\
\hline 3 & Low substituted HPC E5LV & USP/NF, JP & Signet Chemical Corporation, Mumbai \\
\hline 4 & PEG 6000 & LR & Clariant chemicals India Ltd, India \\
\hline 5 & Sodium Lauryl Sulphate & AR & Signet Chemical Corporation, Mumbai \\
\hline 6 & PVP K 30 & LR & Signet Chemical Corporation, Mumbai \\
\hline 7 & Talc & LR & S.D. Fine Chemicals Ltd., Mumbai, India \\
\hline 8 & Isopropyl Alcohol & AR & Loba Chemie Pvt. Ltd., Mumbai, India. \\
\hline 9 & Sodium Bicarbonate & AR & Allied Overseas, Mumbai, India \\
\hline
\end{tabular}

\section{Preformulation Study}

\subsection{Melting point determination:}

Drug substance melting point was checked by using capillary method. Observed value was compared with the reported value.

\subsection{Scanning of carvedilol tartrate in $0.01 \mathrm{~N} \mathrm{HCl}$ :}

The solution having $10 \mu \mathrm{g} / \mathrm{ml}$ of carvedilol tartrate in $0.01 \mathrm{~N} \mathrm{HCl}$ was manufactured and scan over the wavelength range of $200-400 \mathrm{~nm}$ against $0.01 \mathrm{~N} \mathrm{HCl}$ as blank utilizing UV spectrophotometer. A plot of wavelength verses absorbance was recorded using UV spectrophotometer.

\subsection{Standard curve of Carvedilol in $0.01 \mathrm{~N} \mathrm{HCl:}$}

A correct weighing quantity of carvedilol (10 mg) was dissolve in $100 \mathrm{ml}$ of $0.01 \mathrm{~N} \mathrm{HCl}$ to give a stock solution $(100 \mu \mathrm{g} / \mathrm{ml})$. The stocks solution is used to investigate the $\lambda$ max of carvedilol. The aliquots $(0.2-2 \mathrm{ml})$ of the stock solution which further diluted to $10 \mathrm{ml}$ to manufacture standard solutions which have concentrations of $2-20 \mu \mathrm{g} / \mathrm{ml}$. The absorbance of solvents was calculated at $294.5 \mathrm{~nm}$ utilizing double beam UV-Visible spectrophotometer against $0.01 \mathrm{~N} \mathrm{HCl}$ as a blank. The plot of absorbances verses concentration $(\mu \mathrm{g} / \mathrm{ml})$ was plotted and results were subjected for linear regression study in MS Excel. Curve shown in figure 1.

\subsection{Drug-Excipients interaction study:}

\subsubsection{FTIR spectroscopy: ${ }^{10}$}

Infrared spectra-photometry is a useful analytical tool to check chemical interactive action in active substance and various ingredients utilized in composition. A sample (1 mg) was mixed and powdered with $10 \mathrm{mg}$ dry powdered of $\mathrm{KBr}$. The mixing of powder was bringing in a sample and the spectrums were determined by screening in wavelength range of $400-4000 \mathrm{~cm}^{-1}$ using FTIR spectrophotometer. The drugs IR spectrum was compared with physical mix of drug and polymers to found for such possible active substance-excipients interaction.

\subsubsection{Differential Scanning Calorimetry (DSC):}

A DSC (Mettler Toledo, Greifensee, Switzerland) is equipped with an intra-cooler device and refrigerating 
system was utilized to analyze thermal characteristics of carvedilol. Active substance loaded pellets and eudragit coated pellet in the range of 35 to $300^{\circ} \mathrm{C}$. Indium standard were utilized to calibrate temperature of DSC. Nitrogen gas was purging at $50 \mathrm{ml} / \mathrm{min}$ and $100 \mathrm{ml} / \mathrm{min}$ via cooling unit.

2 Preparation of the coated pellets ${ }^{11}$
Fluidized bed processor is a method for the preparation of the coated pellets. In this method; a core material (sugar spheres) is coated with the drug substance following a secondary coating process in which the coating of gas forming agent and tertiary coating of modified release controlling polymer material is performed.

Table 2: Drug loading on sugar pellets

\begin{tabular}{|c|c|c|c|c|c|c|c|}
\hline Sr. No. & Ingredients (gms) & T1 & T2 & T3 & T4 & T5 & T6 \\
\hline 1 & Sugar Pellets (25-30\#) & 50 & 50 & 50 & 50 & 50 & 50 \\
\hline 2 & Carvedilol(API) USP & 1.25 & 1.25 & 1.25 & 1.25 & 1.25 & 1.25 \\
\hline 3 & HPMC E5LV USP & 2 & 4 & 2 & - & 4 & 4 \\
\hline 4 & Low substituted HPC E5LV & 2 & 2 & 4 & 4 & 2 & - \\
\hline 5 & PVP K30 LR & 4 & 2 & 2 & 2 & - & 2 \\
\hline 6 & Sodium Lauryl Sulphate AR & 0.2 & 0.2 & 0.2 & 0.2 & 0.2 & 0.2 \\
\hline 7 & Isopropyl alcohol AR & 20 & 20 & 20 & 20 & 20 & 20 \\
\hline 8 & Talc LR & 1.00 & 1.25 & 1.50 & 1.75 & 2.00 & 1.75 \\
\hline 9 & 0.1 NCL HCL & 60 & 60 & 60 & 60 & 60 & 60 \\
\hline
\end{tabular}

\section{Characterization of Drug Coated Pellets:}

\subsection{Micromeritic Properties:}

The characteristics like angle of repose, bulk density, tapped density, hausner ratio of spheres were checked to evaluate the flowing characteristics of spheres. The angle of repose near to the 20 shows excellent flow and for Hausner's ratio around 1 show good flow properties. 12

\subsection{Morphology of Drug loaded pellets (SEM):}

The morphology of non pareils was checked by SEM. The view of pellets showed a spherical structure with rough surface morphology (Figure 10).

\subsection{Drug content ${ }^{13}$ :}

Content of active substance from sphere formulation was investigated; in that quantity of spheres equivalent to $6.25 \mathrm{mg}$ of dose of active substance was measured and dissolve in $0.01 \mathrm{~N} \mathrm{HCl}$, it is sonicated for fifteen minutes to dissolve it completely and then made the solution of $14 \mathrm{ppm}$ which is consider as a working level for the overall analysis. The absorbance was found at the $294.5 \mathrm{~nm}$ by UV spectrophotometry. The drug content of Batches T1 to T6 is shown in Table 3.

\subsection{In vitro drug release studies:}

In-vitro release of carvedilol from pellet compositions was determined by USP apparatus II (Paddle method). The release medium was $500 \mathrm{ml} 0.01 \mathrm{~N} \mathrm{HCl}$ solution at $37 \pm 0.5^{\circ} \mathrm{C}$ and the rotating speed of the apparatus was set to $50 \mathrm{rpm}$ for all compositions (pellets). At certain time intervals, $1 \mathrm{ml}$ of sample was withdrawn and rapidly equal amount of fresh media $\left(37 \pm 0.5^{\circ} \mathrm{C}\right)$ was changed. For determining of carvedilol quantity, the UV absorbance of samples were calculated at $\lambda \max =294.5$ $\mathrm{nm}$ by UV spectrophotometers and overall quantity of drug released was measured with cumulative percentage active substance release. Percentage cumulative release of drug from coated spheres (T1 - T6) was given in Figure $11 .^{12}$

\section{RESULTS AND DISCUSSION}

\section{Preformulation Study:}

\subsection{Melting point determination:}

The melting point of carvedilol was found $194-196^{\circ} \mathrm{C}$ which complies with the reported value.

\subsection{UV Spectrum of carvedilol tartrate in $0.01 \mathrm{~N}$ HCl:}

UV spectrum of carvedilol tartrate in $0.01 \mathrm{~N} \mathrm{HCl}$ showed that the drug had a $\lambda_{\max }$ of $294.5 \mathrm{~nm}$ that was similar as reported.

\subsection{Standard curve of carvedilol tartrate:}

The standard plot of carvedilol tartrate in $0.01 \mathrm{~N} \mathrm{HCl}$ is shown in fig 11. The correlation coefficient obtained was 0.997 and equation of regression line was $\mathrm{y}=$ $0.0375 x+0.0038$. The standard calibration data shows that the absorbance value increases linearly as the concentration increases.

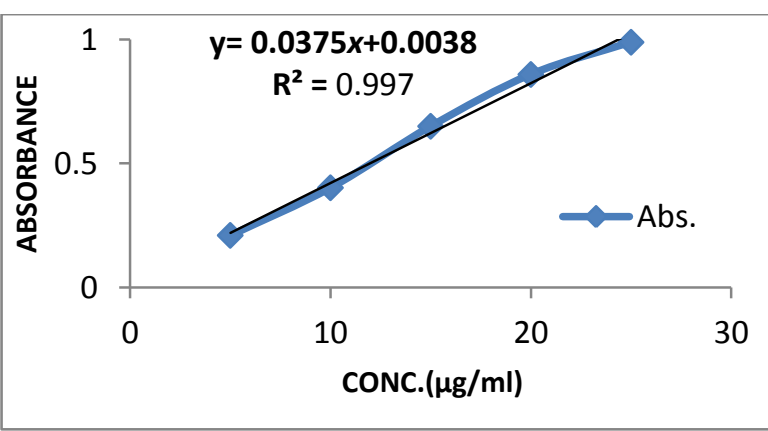

Figure 1: Standard Curve of carvedilol tartrate in 0.01N HCl. 


\subsection{Drug-Excipients Interaction study:}

\subsubsection{FTIR Spectroscopy}

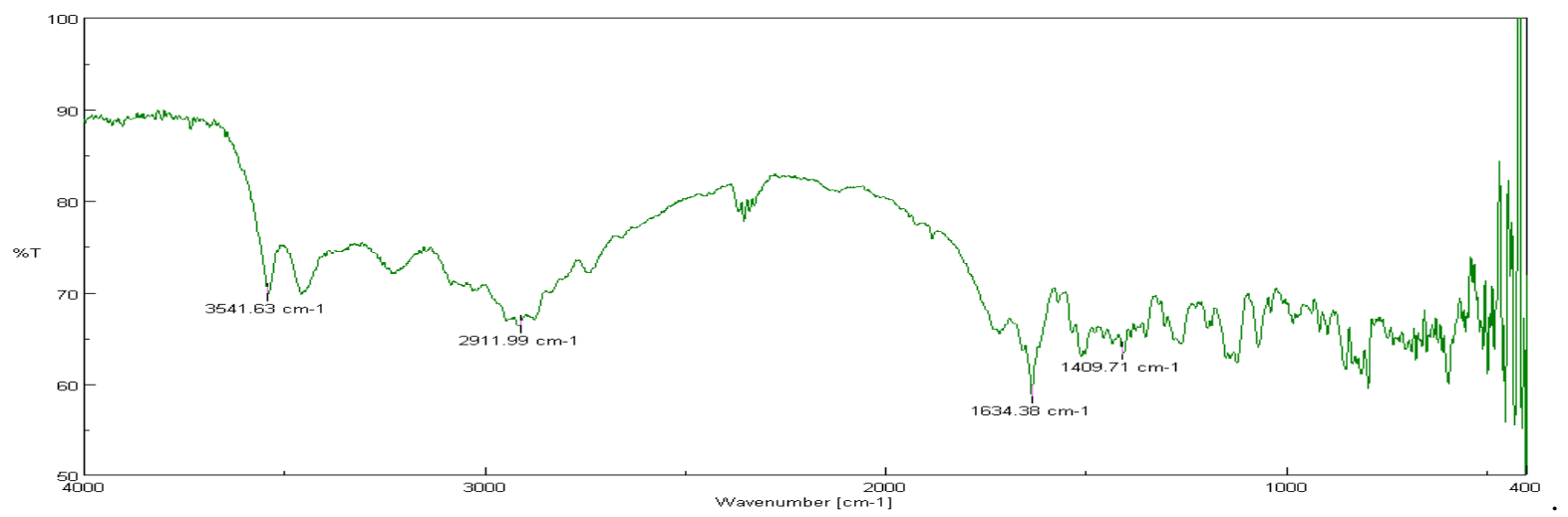

Figure 2: FTIR of Carvedilol

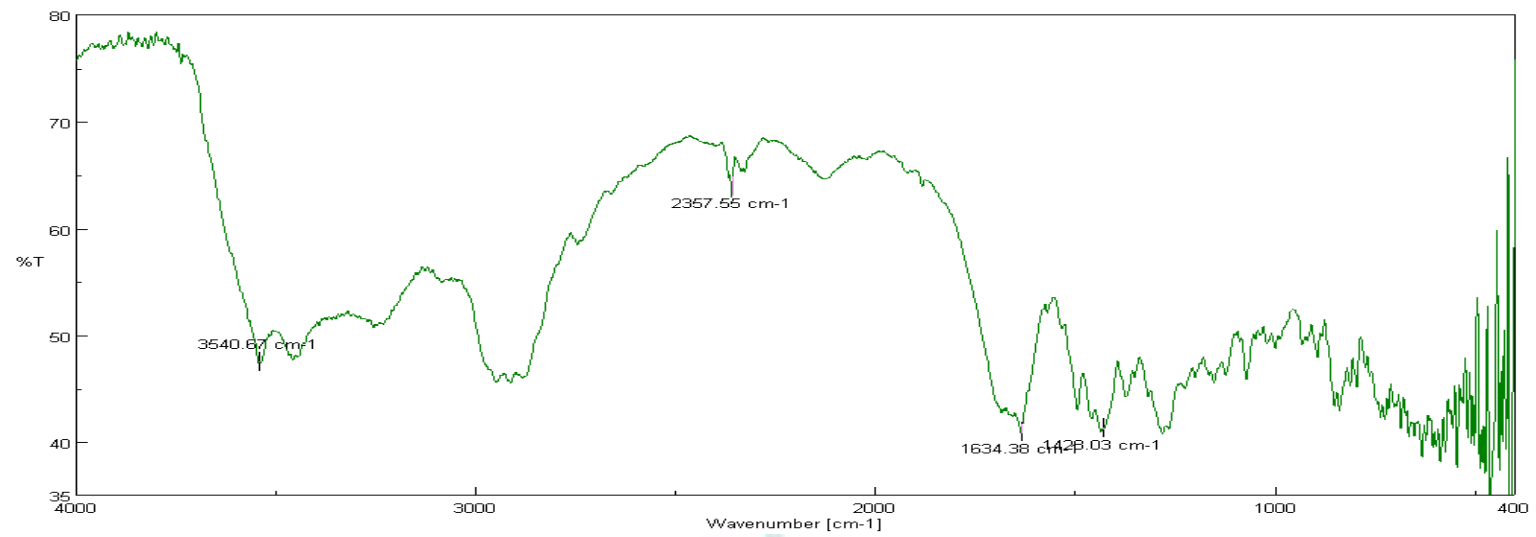

Figure 3: FTIR of Drug: PVP K30

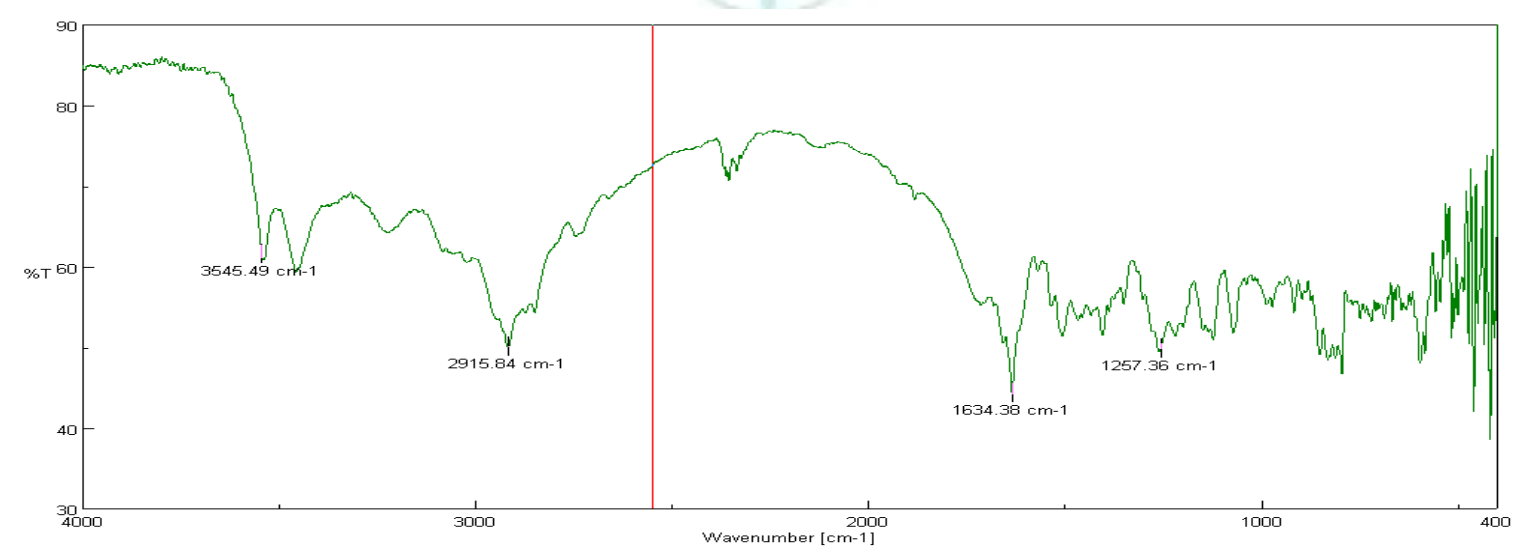

Figure 4: FTIR of Drug: SLS

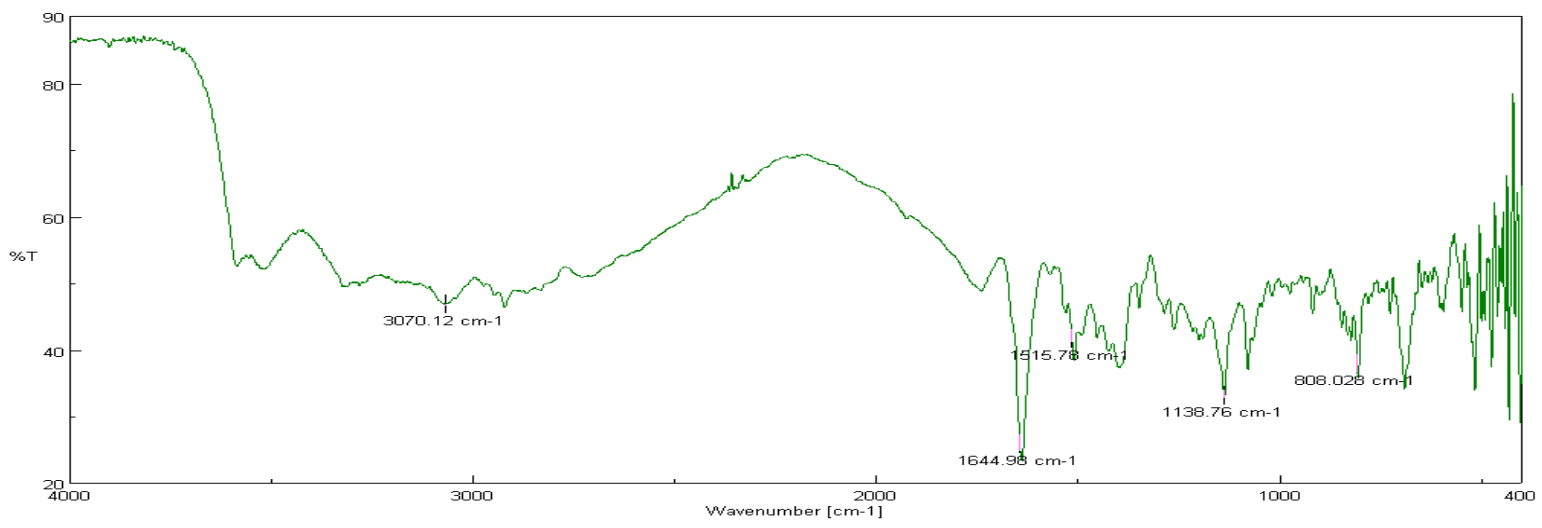

Figure 5: FTIR of Drug: Eudragit NE 40D 


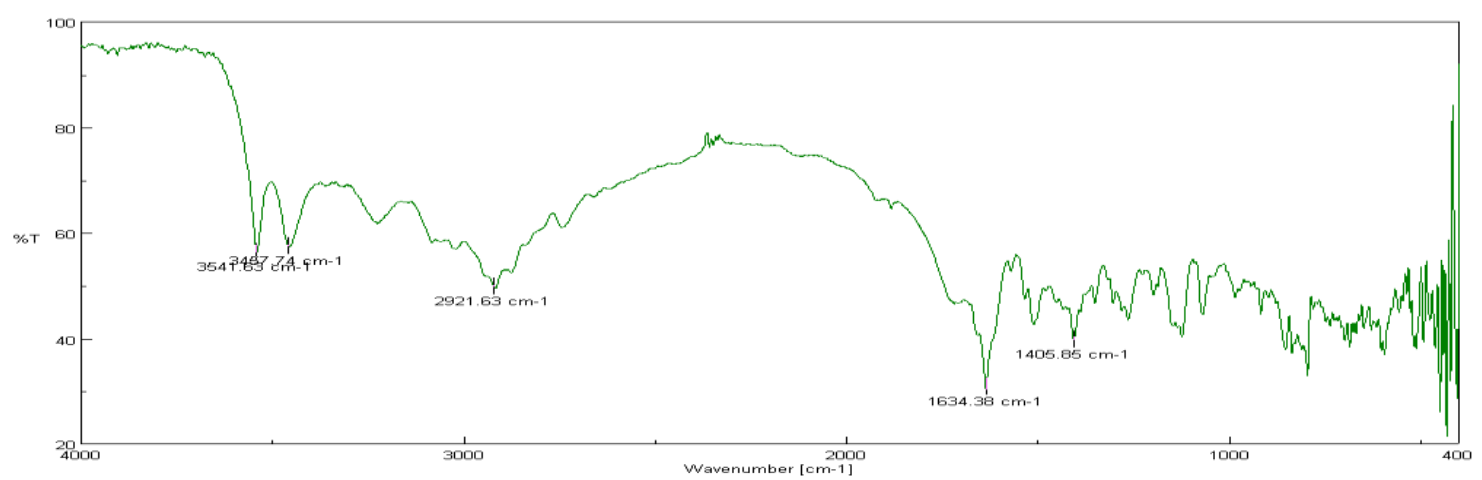

Figure 6: FTIR of Drug: Sodium bicarbonate

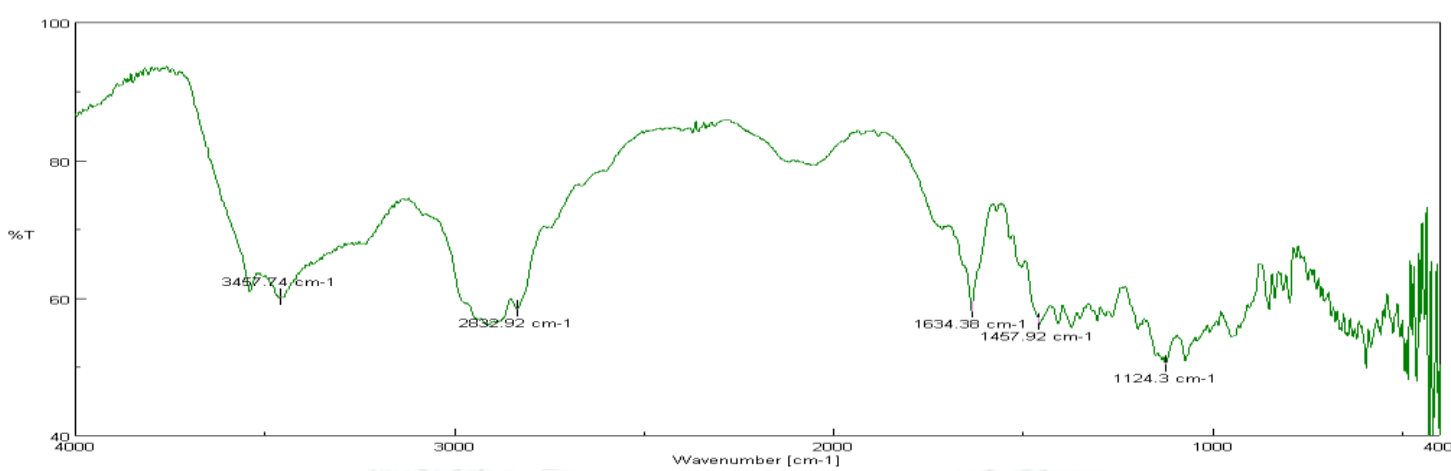

Figure 7: FTIR of Drug: HPMC

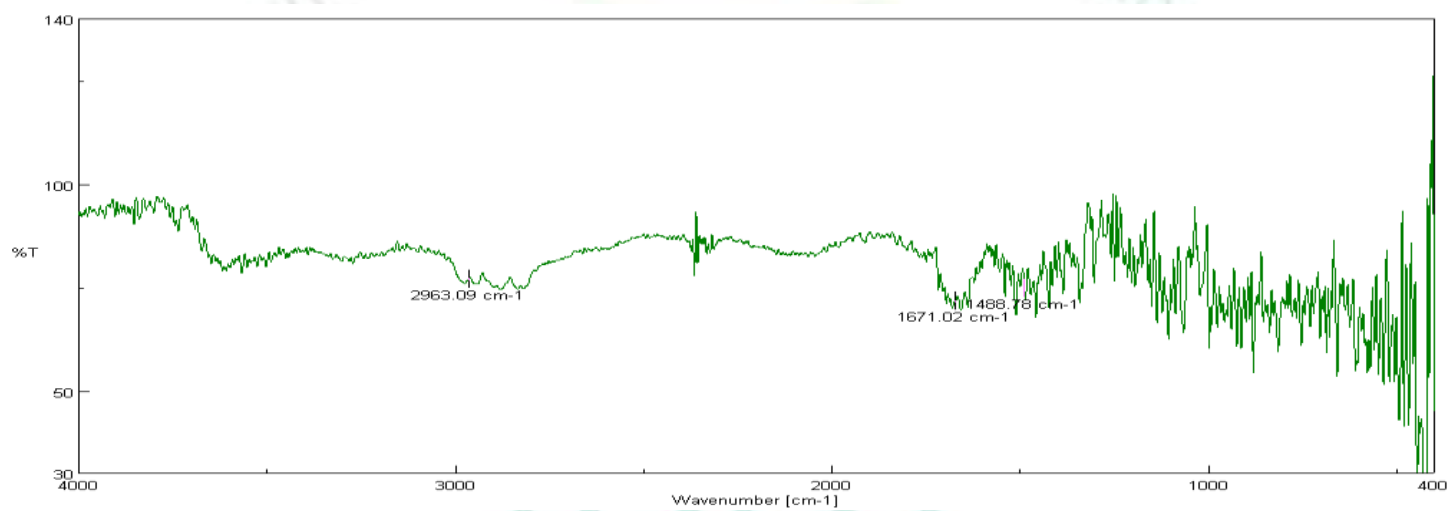

Figure 8: FTIR of Final Optimum Formulation

The FTIR spectra of drug carvedilol tartrate showed OH stretching (bonded) at $3541.63 \mathrm{~cm}^{-1}, \mathrm{CH}$ aliphatic stretching at $2911.99 \mathrm{~cm}^{-1}$ and $\mathrm{C}=\mathrm{O}$ stretching at $1634.38 \mathrm{~cm}^{-1}$.

The HPMC showed OH stretching (bonded) at 3457.74 $\mathrm{cm}^{-1}$ and $\mathrm{CH}$ aliphatic stretching at $2832.92 \mathrm{~cm}^{-1}$.

Sodium bicarbonate showed $\mathrm{OH}$ stretching (bonded) at $3457.74 \mathrm{~cm}^{-1}$ and N-H stretching of NH at $3541.63 \mathrm{~cm}^{-1}$.

Eudragit NE 40D showed C-H stretching of aromatic ring at $3070.12 \mathrm{~cm}^{-1}$ and $\mathrm{C}=\mathrm{O}$ stretching at $1644.98 \mathrm{~cm}^{-1}$.

SLS showed $\mathrm{OH}$ stretching (bonded) at $3545.49 \mathrm{~cm}^{-1}$, $\mathrm{CH}$ aliphatic stretching at $2915.84 \mathrm{~cm}^{-1}$ and $\mathrm{C}=\mathrm{O}$ stretching at $1634.38 \mathrm{~cm}^{-1}$

The IR spectra of drug- excipients mixture shown that prominent peaks of the drug were un-affected or displayed from its original position. Thus no interaction was observe between the active substance and excipients. Hence drug-excipients compatibility was established. There was neither shift nor dis-appearance of properties peaks concludes that there is no any interaction in carvedilol and other ingredients used in the formulation development or no degradation in drug molecule.

The FTIR spectra of active substance and the physical mixture with different ingredients confirmed no presence of the interaction between active substance and the other ingredients. It also assured that the grades of excipients used in formulation are compatible with carvedilol.

On the basis of melting point and FTIR spectrum of drug it is observed that the procured carvedilol was pure and it was free from any type of degradation product or any type of impurities.

\subsubsection{Differential Scanning Calorimetry}

DSC study was conducted to check the identity and purity of the Carvedilol. 


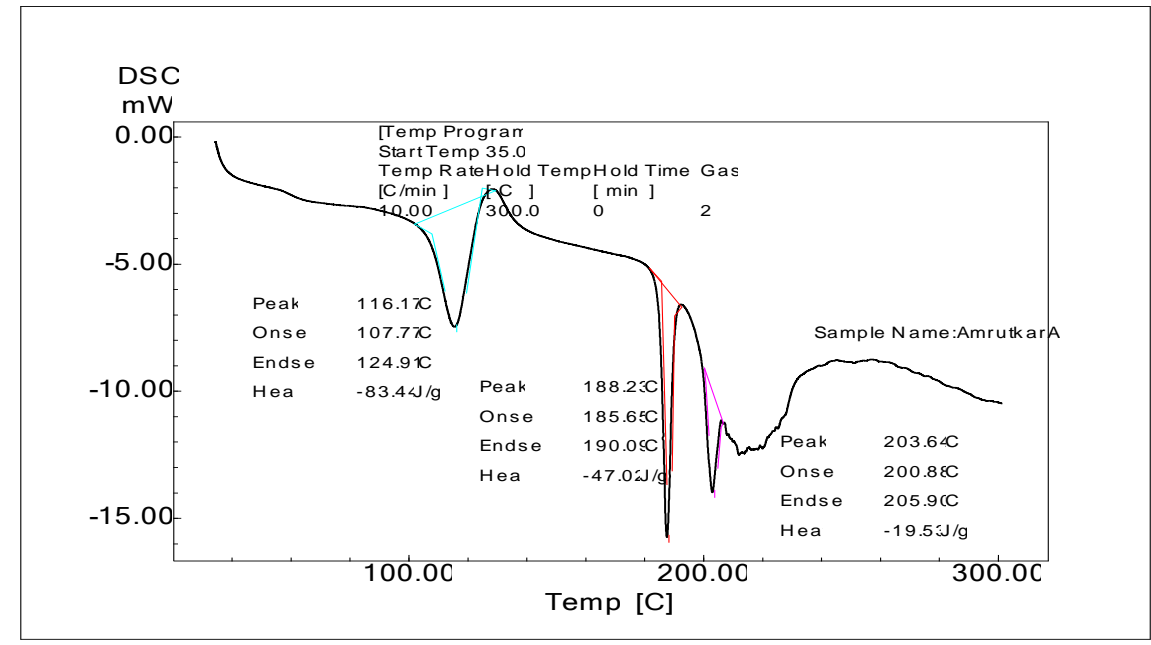

Figure 9: DSC of Carvedilol

On the basis of melting point, DSC study and FTIR spectrum of drug it is observed that the procured carvedilol was pure and it was free from any type of degradation product or any type of impurities.

\section{Characterization of Drug Coated Pellets:}

\subsection{Micromeritic Properties:}

The results obtained for micromeritic properties of drug loaded spheres are shown in Table 3. The angle of repose near to the 20 shows excellent flow and for hausner ratio around 1 show good flow properties ${ }^{14,15,16}$. The results obtained for micromeritic characteristics of active substance loaded pellets showed good to excellent flow behavior.

Table 3: Micromeritic properties of drug loaded pellets

\begin{tabular}{|c|c|c|c|c|}
\hline Formulation Batches & Bulk density* (gm/ml) $^{*}$ & Angle of repose* $^{*}$ & Hausner ratio* $^{*}$ & Drug content* (\%) $^{\text {(\%) }}$ \\
\hline T1 & $0.813 \pm 0.124$ & $23.54 \pm 0.325$ & $1.04 \pm 0.254$ & $98.59 \pm 0.24$ \\
\hline T2 & $0.798 \pm 0.247$ & $18.37 \pm 0.412$ & $1.07 \pm 0.264$ & $96.74 \pm 0.15$ \\
\hline T3 & $0.853 \pm 0.217$ & $21.09 \pm 0.428$ & $1.05 \pm 0.213$ & $97.15 \pm 0.31$ \\
\hline T4 & $0.809 \pm 0.301$ & $20.17 \pm 0.364$ & $1.03 \pm 0.398$ & $102.53 \pm 0.31$ \\
\hline T5 & $0.782 \pm 0.103$ & $23.93 \pm 0.256$ & $1.05 \pm 0.512$ & $100.39 \pm 0.14$ \\
\hline
\end{tabular}

*Mean \pm S.D. $(\mathrm{n}=3)$

\subsection{Morphology:}

The morphology of non pareils was checked by SEM. The view of pellets showed a spherical structure with rough surface morphology (Figure 10). After coating of non pareils, smooth surface of pellets was observed. SEM study at X100 as well as X60 magnifications revealed that the active substance layered spheres are dense with wrinkled, rough and porous circumference which is due to gradual loss of aqueous material during active substance layering process from the surface of spheres.

\subsection{Drug content}

The drug content of Batches T1 to T6 is shown in Table 3. The active substance content of drug loaded pellets was find to be $96.00 \%-105 \%$ for T1 -T6 which was within the limits (Std. limits- 95\% - 105\%)
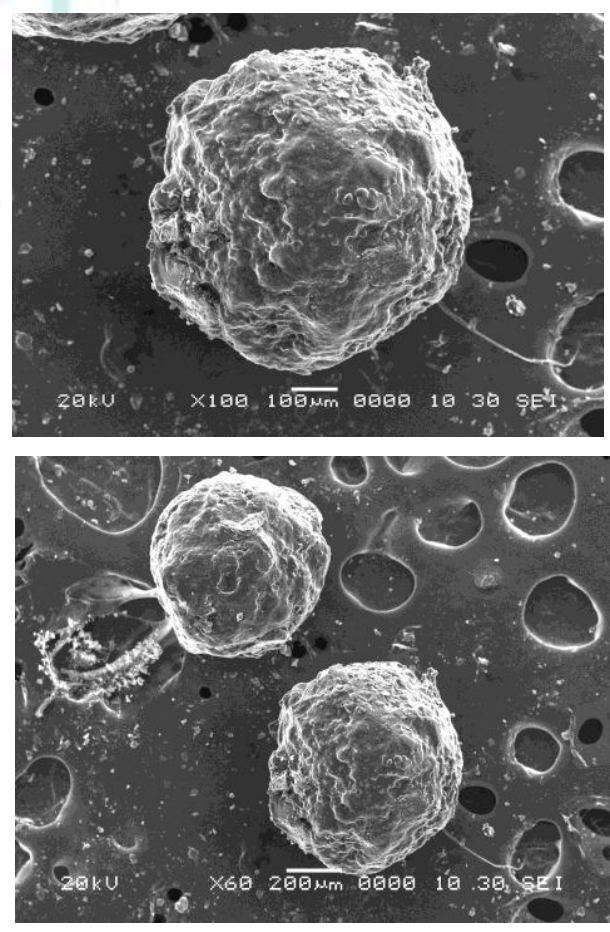

Figure 10: SEM photograph of drug loaded pellets 


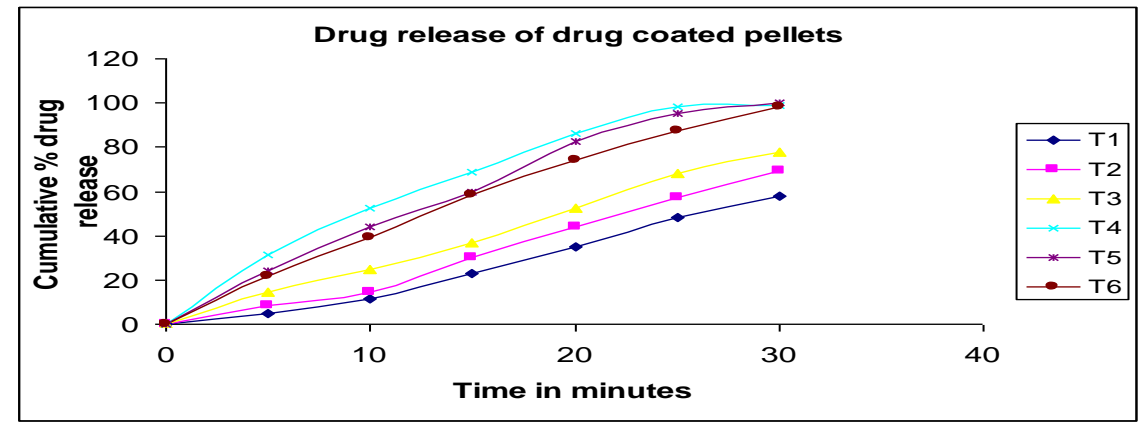

Figure 11: Drug release of drug loaded pellets

The release pattern of the drug loaded pellets is given in Figure 11. In vitro release trials were performed to check the release of active substance from drug coated spheres. The releasing profile of batches $\mathrm{T} 1$ to $\mathrm{T} 6$ was noted to vary due to changes in the quantity of HPMC $5 \mathrm{Cps}$, lower substituted HPC and PVP K30. The batches T1-T3 gives the minimum active material release due to combination of PVP K30 with lower substituted HPC and HPMC 5 cps; while the composition T4-T6 gives the better release pattern as compare to T1-T3. From the figure 11, it was shown that, the combination of low substituted HPC, HPMC 5cps and PVP K30 lowers the active substance release while combination of PVP K30 either with lower substituted HPC or HPMC 5cps gives better active substance release. Based on active substance release pattern, the composition T6 was chosen for further subcoating batches.

\section{CONCLUSION:}

The layering stage includes depositing of successive layering of active entities from suspension or solution on nuclei (pellets of inert material/sugar spheres). Solution layering includes depositing of respective layers of solutions of active materials on pellets. As the solution was sprayed onto the product bed, the droplets come in contact with cores and spread over surface evenly, shown that fluid dynamics and drying stages are favorable. This is following the drying stage which permits crystallizing dissolving substances and forming solid bridge in core and primary layer of active substance and between successive layers of active substance. This process continues until appropriate layers of active substance and hence target potency of spheres is achieved. A solution consists of polymer which used to increase the binding efficiency of drug substance. Polyvinyl pyrrolidone was used as a binding agent. Talc was used as glidant, antiadherants or antisticking agent. Sodium lauryl sulphate acts as a wet former.

In vitro release trials were evaluated in response to check release of drug from the drug coated spheres. The release pattern of batches T1 to T6 was observed to vary due to variation in the concentration of HPMC $5 \mathrm{cps}$, low substituted HPC and PVP K30. The trials T1-T3 showed the slow drug release due to combination of PVP K30 with low substituted HPC and HPMC 5cps; while the formulation T4-T6 showed the good release behavior as compare to T1-T3. From the figure 11 it was found that, the combination of HPMC 5cps, low substituted HPC and PVP K30 decreases the drug release while combination of PVP K30 either with low substituted HPC or HPMC 5cps shows better drug release. Based on drug release study, the formulation T6 was selected for further sub-coating trials.

\section{REFERENCES:}

1. Rastogi V, Shukla S, Singh R, Lal N, \& Yadav P. Microspheres: a promising drug carrier. Journal of Drug Delivery and Therapeutics, 2016; 6(3):18-26. doi:10.22270/jddt.v6i3.1196

2. Kappor D, Patel M, Vyas R, Lad C, \& Tyagi B. A review on microsponge drug delivery system. Journal of Drug Delivery and Therapeutics, 2014; 4(5):29-35. doi:10.22270/jddt.v4i5.978

3. Kapoor, D. Fabrication and characterization of non steroidal antiinflammatory alginate beads for sustained release using natural polymer. Journal of Drug Delivery and Therapeutics, 2017; 7(2):77-80. doi:10.22270/jddt.v7i2.1401

4. Thakkar H, Patel N, Amodwala S. Formulation development of controlled release mucoadhesive beads of capecitabine. Journal of Drug Delivery and Therapeutics, 2016; 6(3):42-50. doi:10.22270/jddt.v6i3.1252

5. Kajale A, Chandewar A. Formulation and evaluation of oral floating beads of tramodol hydrochloride. Journal of Drug Delivery and Therapeutics, 2016; 6(4):7-16. doi:10.22270/jddt.v6i4.1270

6. Shaji J, Chadawar V, Talwalkar P. Multiparticulate Drug transport system. The Indian Pharmacist. 2007; 6(60):21-28.

7. Zhang Z. Multi-Component Drug Delivery of Paclitaxel. Journal of Drug Delivery and Therapeutics, 2017; 7(3):80-83. doi:10.22270/jddt.v7i3.1451.

8. Laila F, Chandran S. Multiparticulate formulation method to colon specific drug delivery cutting-edge perspectives. J. Pharm Pharm Sci. 2006; 9(3):327-338.

9. Shah D, Patel B, Shah C. Nanosuspension technology: a innovative slant for drug delivery system and permeability enhancer for poorly water soluble drugs. Journal of Drug Delivery and Therapeutics, 2015; 5(1):10-23. doi:10.22270/jddt.v5i1.995.

10. Schmidt C, Bodmeier R. A multiparticulate drug-transport system based totally on pellets included into congealable polyethylene glycol carrier substances. Int. J. Pharm. 2001; 216: 9-16.

11. Schmidt C., Kleinebudde P. have an impact on of the granulation step on pellets prepared via extrusion/ Spheronization. Chem. Pharm Bull. 1999; 45 (3): 405-412.

12. Agarwal D, Ranawat M, Chauhan C, Kamble R. Formulation and charecterisation of colon targeted $\mathrm{pH}$ dependent microspheres of capecitabine for colorectal cancer. Journal of Drug Delivery and Therapeutics, 2014; 3(6):215-222. doi:10.22270/jddt.v3i6.747

13. Mehta AM, Valazza MJ, Abele SE. evaluation of fluidizedmattress methods for enteric coating systems. Pharm. Technology. 1986; 46- 48.

14. Patil S, Gupta V. Design and in vitro evaluation of multiparticulate system for the chronomodulated delivery of lornoxicam. Journal of Drug Delivery and Therapeutics, 2015; 5(3):62-71. doi:10.22270/jddt.v5i3.1148

15. Thoma okay, Ziegler I. The $\mathrm{pH}$ independent release of fenoldopam from pellets with insoluble film coats. Eur J Pharm and Biopharm. 1998; 47(1):105-113.

16. Umprayn OK, Chitropas P, Amarekajorn S. development of terbutaline sulphate sustained release lined pellets. Drug Dev. Ind. Pharm. 1999; 25(4):477-491. 